\title{
Exploration on the Blended Teaching Model of Safety System Engineering Based on the Cultivation of Innovative Ability
}

\author{
Li Lifeng, Shi Junwei, Dong Yu \\ School of Management Science and Engineering, Shandong Technology and Business University \\ Yantai, Shandong, China
}

\begin{abstract}
Innovation is the primary driving force for development. To seek innovation is to seek the future. Innovative ability is the basic demand for talents in modern society. Higher education should combine modern information technology with traditional teaching to cultivate innovative talents with innovative thinking and ability. Taking the core course of safety engineering-safety system engineering as an example, this paper explores the blended teaching mode based on the cultivation of innovative talents, in order to improve the teaching effect and cultivate students' innovative thinking and creativity.
\end{abstract}

Keywords - blended teaching; innovative thinking and creativity; talents cultivation

\section{INTRODUCTION}

Development is the first priority, the talented people is the primal resource, and innovation is the first driving force. Promoting college students' innovative consciousness and ability-training of innovative talents have gradually become the focus of higher education reform, so as to achieve the goal of rejuvenating the nation ${ }^{[1]}$. To promote the healthy development of innovative education, it is necessary to improve the cultivation system of innovative education, which includes building up innovative consciousness, cultivating innovative spirit, perfecting knowledge structure and mastering professional skills. The teaching links in colleges and universities play a direct guiding role in this system. Using modern convenient information technology and mobile digital terminal equipment widely used by teachers and students, by changing the teaching process and the teaching mode, we can increase the evaluation elements to promote the development of students' high-level thinking and the cultivation of innovative talents ${ }^{[2]}$. The blended teaching mode is a new teaching mode based on the integration of modern information technology and traditional classroom teaching mode.

\section{The General ThOUght OF BLENDED TEACHING}

Safety system engineering is a comprehensive and crossdisciplinary major with a wide range of fields. In the process of formulating the training plan, the goal is to train applied talents with innovative, practical and employmententrepreneurship ability. In the teaching process, the blended teaching mode can stimulate students' interest in learning, enhance their confidence in learning, as well as enhance their

The blended teaching course project 2017 "Safety system engineering" supported by Shandong Technology and Business University participation and enthusiasm, thereby the teaching objectives can be better achieved.

Blended teaching can solve the drawbacks of passive learning in traditional teaching mode. In traditional teaching, teachers are the mainstay of classroom teaching, and students lack the link to independent thinking and active learning. Less intercommunion between students and teachers or among students, which lead to low participation of students. Students are reluctant to participate in the later stage of experiment and extracurricular exploration, problems arising in teaching safety system engineering are of primary importance, which include: monotony of teaching methodology, low efficiency, lack of interest on the students' part, and lack motivation on the teachers' part. It is difficult to achieve the original goal of cultivating practical and innovative ability.

China is in the third wave of information construction, information technology and production and life are deeply integrated, mobile phones and other digital terminal devices "run rampant" in the classroom, seriously affecting the classroom teaching order and learning efficiency. "Blocking" is better than "dredging". Instead of pursuing and blocking, it is better to make the best use of everything, make use of the modern network teaching platform, change the teaching mode, so as to enhance students' interest and participation in learning

\section{THE CONSTRUCTION OF BLENDED TEACHING MODEL ORIENTED TOWARDS INNOVATIVE ABILITY CULTIVATION}

\section{A. Pre-class Preparation Stage}

Safety system engineering has the following feature such as wide range, strong practicability, application of new technology and method and developmental trend of comprehensive system.the theory is difficult to understand, resulting non-active, no goal when students learn the course, ultimately the teaching is ineffective ${ }^{[3]}$. Therefore, aiming at these problems, corresponding strategies have been brought forward in the pre-class preparation stage: at first, teachers should contact the curriculum system, analyze the learning situation and master the difficulties of students in the course learning based on the method of network questionnaires. Then,specific solutions should be concluded and the teaching process should be formulated according to the analyzing results $^{[4]}$. We can increase the proportion of case-teaching when using learning resources for teaching design, teachers should center on teaching aim, emphasize and acquire 
these contradictions to make arrangements for quizzing so that they can stimulate the students to learn their own initiative, think actively and create boldly. These measures can achieve the goal of improving their active learning attitude and selflearning ability.

\section{B. Implementation Stage in Class}

We can flexibly use network teaching platform, new media and other network teaching means to carry out the blended teaching mode of "pre-class (online) preview, in-class (offline) interaction and after-class (online) review and expansion". In view of the problem that students will not learn independently after class, we should set up classroom interaction links and let students use online materials to study independently before class in order to cultivate students' independent thinking ability and active learning ability. While designing the tasks in classroom, some simple knowledge points are set up as interactive teaching methods, such as questions, discussion between teachers and students, role transformation, etc. The students' subjective initiative is brought into play under the guidance of questions, so that they can become the protagonists of the classroom, stimulate innovative thinking, and give extra points to the students who speak enthusiastically, so as to mobilize them. Students' enthusiasm for pre-class preparation. After class, students are guided to review by homework, learning notes and innovative design ${ }^{[5]}$. The organization pattern is shown in Figure 1.

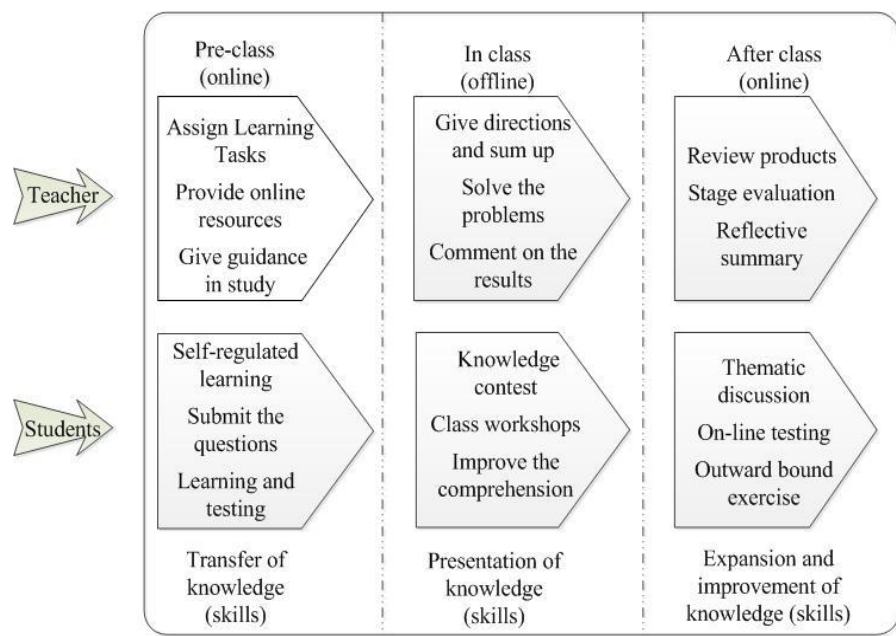

Fig. 1. The Flow-process Diagram of Blended Learning Process Based on Flip Classroom

Online resources are used to expand classroom knowledge after class by strengthening "case-teaching". We upload relevant background knowledge, security situation and development frontier online to help students to understand the system that need to analysis, and explain the application of analytical methods in the system in class. Choose similar cases as homework, and after the students complete, choose some to explain in class and discuss with each other, forming a model of full participation and joint discussion. Through this way of teaching, it plays a role of deepening the integration of theory with practice, diverting innovative thinking, exerting creativity and improving teaching effect. The design of teaching link is shown in Fig $2^{[5][6]}$.

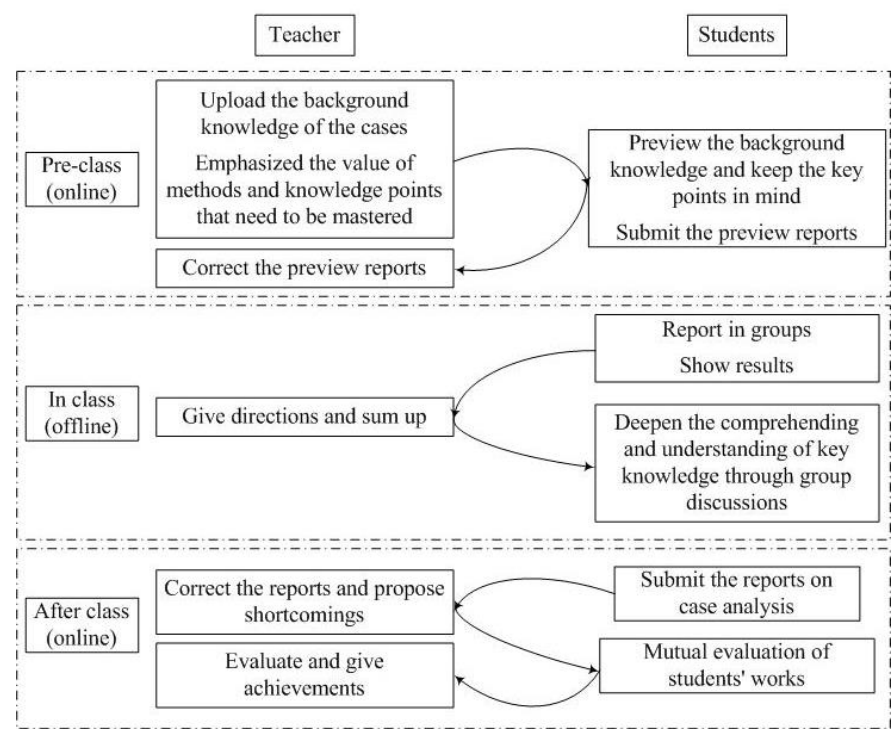

Fig. 2. The Flow-process Diagram of case-teaching

\section{Diverse curriculum evaluation methods}

In order to improve students' interest in learning, increase their confidence in learning and enhance the effectiveness of teaching evaluation, we should also change the way of evaluating students in the form of paper papers while changing the teaching mode, pay more attention to "process control", follow the principles of development, motivation and comprehensiveness, and adopt diversified ways to assess the curriculum $^{[7]}$. There are two parts in the specific assessment indicators.

1) We can set up students' curriculum learning archives, which include normal tests, question answering model, excellent assignments, achievements, process materials of cooperation between students and others, contests and activities related to participation and curriculum learning, problems and difficulties in learning, and what help they hope to get, results of self-evaluation and others' evaluation, good questions and suggestions put forward by students, rewards received, classes Attendance rate, etc (as shown in Figure 3). These measures will encourage students to study independently and give full play to their individual initiative.

2) Paper and pencil tests should be used for the sake of fairness for all students. According to the needs of the curriculum, this traditional assessment method should be improved accordingly. The emphasis of the assessment is not on the simple memory and repetition of knowledge points, but on the comprehensive assessment and evaluation of students' deep understanding, analytical ability, application ability and creative ability from the overall connection of knowledge.

Teachers can improve students' practical innovation ability, vocational skills and quality, and lay a certain foundation for adapting to vocational posts and continuing learning through this diversified evaluation system. 


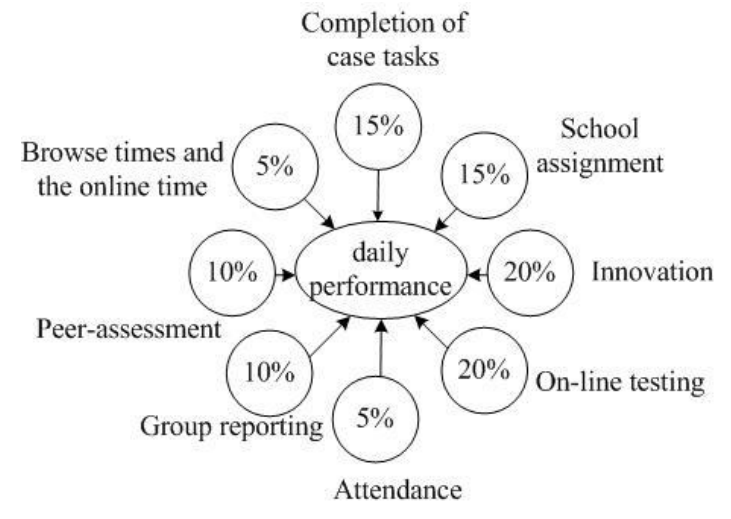

Fig. 3. Composition and Value Distribution of Student Learning Course Archives Based on the Blended Teaching Model

\section{THE APPLICATION OF BLENDED TEACHING MODEL BASED ON THE CUlTIVATION OF INNOVATIVE ABILITY}

\section{A. Increasing interest in learning}

The knowledge of safety system engineering course is practical, and it is easy to remember the knowledge points clearly in the course of theoretical study, but it is not understood. If things go on like this, students' interest in learning has declined, their professional identity has declined. The application of blended teaching model in the preparation of online courses can solve the shortcomings of large classes that can not be taught: According to the analysis of learning situation, making online video materials based on different difficulties as supplementary resources for classroom teaching, students can make use of fragmented time and mobile device clients to study knowledge weak links at any time and anywhere according to their individual situation. We can increase the difficulty of learning step-by-step, help students sort out the knowledge structure, enhance learning efficiency, not only can improve students' interest in learning, but also cultivate their creativity and exploratory spirit, help students develop good habits of independent learning, and lay a good foundation for cultivating innovative ability.

\section{B. Cultivating innovative thinking}

In the teaching process of safety system engineering, students are guided to explore knowledge in depth by means of group cooperation, mutual examination and mutual evaluation. Students can constantly observe and think from different angles, so as to improve their ability to discover and solve problems, activate innovative consciousness, and ultimately strengthen their comprehensive ability. In addition, when explaining new knowledge, teachers should review the knowledge they have learnt in the past by means of the summary of the previous situation, and use the connection between new and old knowledge to lead out new knowledge and effectively guide students to solve new problems through the knowledge they have learnt. Alternating learning of new and old knowledge can activate students' divergent thinking and enhance their flexibility and leap of thinking. Only letting students to think deeply, can arouse their desire to explore knowledge and promote the cultivation of innovative thinking.

\section{Enhancing the use of knowledge}

In the teaching process of safety system engineering, we should also consider the connection and application of professional knowledge and new technology. Blended teaching can reasonably arrange the proportion distribution of learning in and out of class, and increase the knowledge of new technology and new technology after class. In this way, on the basis of learning the basic theory, through new technical means to identify and analyze the risk factors in engineering practice, and understand the impact of new technologies and processes, evaluate and control the risk, so as to achieve the desired goal of system security. In extracurricular practice, it is necessary to combine the theoretical analysis method in the course with practical engineering technology, perfect the connection between theory and practice, enhance the ability of knowledge application, and cultivate students' innovative thinking from the side, so that students can face practical problems in specific situations, strengthen the ability of knowledge application and realize knowledge. Internalization promotes the continuous improvement of innovation ability.

\section{CONCLUSION}

It was discovered by practices that the blended teaching mode based on the training of innovative talents can enable students to continue exploring and learning, constantly explore the potential and advantages of students, better accomplish the training objectives of safety engineering specialty, and cultivate applied talents with innovative consciousness and innovative ability to meet the needs of society.

\section{ACKNOWLEDGMENT}

This work was financially supported by the 2017 blended teaching course project "Safety system engineering" of Shandong Technology and Business University.

\section{REFERENCES}

[1] W. Zhanren, "Debate and Reflection on the Comprehensive Promotion of Innovation and Entrepreneurship Education in Colleges," vol13, Research in Educational Development, 2015, pp. 113-118.

[2] T. Aili, "Transforming Teaching Mode to Promote the Cultivation of Top-notch Innovative Talents" Educational Research, October,2016, pp.106-112.

[3] Z. Jing, W Pengfei, and G Tianbao, "Research on the Teaching Model of Safety Systems Engineering Focusing on the Cultivation of Applied Ability" The Science Education Article Collects, March, 2019, pp.92-93.

[4] Y. Yongjun, Y. Xiuwu, J. Fuliang, "Teaching Content Optimization and Teaching Method Reform of "Safety Systems Engineering"'" 7th ed,vol.3. The Guide of Science \& Education, 2017, pp. 124-126.

[5] L. Xiang, C. Chao, T. Cheng, "A Study on the Blended Teaching Model of Mu-class Based on the Cultivation of Applied Innovative Talents", vol.15. Journal of Anhui Agricultural Sciences, 2018, pp. 234-236.

[6] L. Qiguang, "On the Reform of Blended Teaching Based on the Cultivation of Innovative Thinking", vol.2. Art Science and Technology, 2018, pp.47.

[7] Su. Youju, "Exploration on the Blended Teaching Model of Higher Mathematics Based on the Cultivation of Innovative Ability", 28th, vol.10. Learning Weekly, 2018, pp.15-16. 